\title{
Epidermal necrolysis: SCORTEN performance in AIDS and non-AIDS patients ${ }^{*}$
}

\author{
Carlos Gustavo Wambier ${ }^{1,2}$, Thaís Angélica Hoekstra ${ }^{1}$, Sarah Perillo de Farias Wambier ${ }^{1}$, \\ Roberto Bueno Filho², Fernando Crivelenti Vilar ${ }^{3}$, Renato Soriani Paschoal'2, Ana Maria Roselino², \\ Marco Andrey Cipriani Frade ${ }^{2}$, Norma Tiraboschi Foss ${ }^{2}$
}

DOI: http:/ / dx.doi.org/10.1590/abd1806-4841.20196864

\begin{abstract}
BACKGROUND: Stevens-Johnson syndrome and toxic epidermal necrolysis are life-threatening blistering drug reactions with high incidence of ocular sequela. The term 'Epidermal Necrolysis' has been recently used to better describe the full spectrum of the disease that includes Stevens-Johnson syndrome and toxic epidermal necrolysis at opposite ends, which differ by the extent of body surface area with epidermal detachment. SCORTEN is a mortality prognosis score for 'Epidermal Necrolysis' cases that still needed validation in acquired immunodeficiency syndrome.

ОвлестIVE: To evaluate the SCORTEN performance in acquired immunodeficiency syndrome, and the differences in outcomes between acquired immunodeficiency syndrome and non- acquired immunodeficiency syndrome cohorts.

Methods: Retrospective cohort study of AIDS and non-AIDS 'Epidermal Necrolysis' cases admitted to a Brazilian reference center from 1990-2014.

RESULTS: Five deaths (16.7\%) occurred as a consequence of EN in 30 AIDS patients, and seven (17.9\%) in 39 non-AIDS patients, relative risk (RR) $92(\mathrm{p}=1.0)$. SCORTEN showed great performance, with an Area Under the Receiver Operating Curve (AUC) (ROC) of 0.90 with a 95\% confidence interval ranging from .81 to .99. The performance of SCORTEN was better among nonAIDS patients than AIDS patients: AUC non- acquired immunodeficiency syndrome $=0.99$ (CI 05\% 0.96-1.00), AUC acquired immunodeficiency syndrome $=0.74($ CI 95\% 0.53-0.95), $\mathrm{p}=.02$.

STUDY LimitATIONS: Heterogeneity of cases, wide variation of systemic corticosteroid doses when used.

CONCLUSION: SCORTEN is valid for the Brazilian population, including among those patients with acquired immunodeficiency syndrome, and, as such, its use is recommended for aiding treatment choice in this subgroup of patients.

Keywords: Acquired immunodeficiency syndrome; Epidermal necrolysis, toxic; Hospitalization; Length of stay; Lethality; Scales; Stevens-Johnson syndrome
\end{abstract}

\section{INTRODUCTION}

Stevens-Johnson syndrome (SJS) and toxic epidermal necrolysis (TEN) are life-threatening blistering mucocutaneous reactions usually triggered by drug exposure. ${ }^{1}$ These diseases are now considered to be different points on the spectrum of a single disease, with TEN representing the most severe expression of the condition. ${ }^{2}$ The term 'Epidermal Necrolysis' (EN) has been recently used to bet- ter describe the full spectrum of disease that includes SJS and TEN at opposite ends, which differ only by the percentage of body surface area of epidermal detachment (SJS $<10 \%$ and TEN $>30 \%$ ), and, therefore, by severity. ${ }^{3}$ Data suggest that the pathogenesis of EN is mediated by medication-induced cytotoxic response by T-cells triggered by drugs, which results in keratinocyte apoptosis, possibly

\footnotetext{
Received 28 December 2016.

Accepted 26 November 2017.

* Work conducted at the Department of Medicine, Universidade Estadual de Ponta Grossa, Ponta Grossa (PR), Brazil; Hospital das Clínicas, Faculdade de Medicina de Ribeirão Preto, Universidade de São Paulo, São Paulo (SP), Brazil.

Financial support: None.

Conflict of interest: None.

Department of Medicine, Universidade Estadual de Ponta Grossa, Ponta Grossa (PR), Brazil.

Division of Dermatology, Department of Internal Medicine, Universidade Estadual de Ponta Grossa, Ponta Grossa (PR), Brazil.

Division of Infectious and Tropical Diseases, Department of Internal Medicine, Faculdade de Medicina de Ribeirão Preto, Universidade de São Paulo, São Paulo (SP), Brazil.
}

MAILING AdDREsS:

Carlos Gustavo Wambier

E-mail: cwambier@usp.br 
due to modifications in major histocompatibility complex I proteins by non-covalent binding of the offending drug to specific human leucocyte antigens (HLA), leading to CD8+ T-cell activation. ${ }^{3-5}$

Despite being rare, this disease presents high lethality (12$46 \%$ ), and high morbidity, with generalized infections, sepsis, and disseminated intravascular coagulation as the major acute adverse events, and ocular scars as main chronic sequela., $3,6,7$ The severity of such events imposes the significance of adequate management. Corticotherapy, ${ }^{8,9}$ intravenous immunoglobulin therapy, ${ }^{10,11}$ and cyclosporine- $\mathrm{A}^{12}$ have been proposed as treatments; however, there is still no consensus or guidelines about their use, nor satisfactory treatment trials to further evaluate the true impact of such therapies. $4,8,13,14$

Bastuji-Garin et al analyzed French patients diagnosed with EN and proposed a score to determine prognosis: the SCORTEN..$^{15}$ (Table 1). This score was initially tested in France; however, it is known that the clinical management of EN patients may vary according to the country and hospital they are admitted to. ${ }^{8}$ It has been argued that this might render the SCORTEN less reliable when applied to different populations, thus invalidating studies that use it as a tool to predict mortality rates. Despite that, SCORTEN has been validated for its use in the United States of America, ${ }^{16}$ Korea, ${ }^{17}$ Canada, ${ }^{18}$ and China. ${ }^{19}$

The purpose of this study was to evaluate the performance of SCORTEN as mortality predictor in acquired immunodeficiency syndrome (AIDS) and to analyze differences in outcomes between AIDS and non-AIDS Brazilian cohorts.

\section{METHODS}

A retrospective cohort was performed by review of hospital charts. Patients included in this study were all those with or without AIDS, admitted to a tertiary level, university hospital in Brazil that fulfilled the criteria for clinical diagnosis of SJS-TEN ${ }^{2}$ (EN) from January 1990 to December 2014. A total of 155 patients were initially selected by retrieving all inputs in the hospital electronic medical charts of diagnoses: L51.1, L51.2, and B20 (10 th revision of the International Code of Diseases).$^{20}$ All patients with dubious or incorrect diagnosis were excluded, such as no description of mucosal involvement, non-blistering exanthema, erythema multiforme, psoriasis, pemphigus vulgaris, bullous pemphigoid, and paraneoplas-

TABLE 1: SCORTEN - Score for Toxic Epidermal Necrolysis

Risk factors add 1 point if present:

\begin{tabular}{ll}
\multicolumn{2}{c}{$\cdot$ Detachable Skin Surface Area $>10 \%$} \\
$\cdot$ neoplasia & $\cdot$ urea $>28 \mathrm{mg} / \mathrm{dL}$ \\
$\cdot$ HR $\geq \mathbf{1 2 0} \mathbf{b p m}$ & $\cdot$ serum glucose $>252 \mathrm{mg} / \mathrm{dL}$ \\
$\cdot$ age $>\mathbf{4 0}$ years & $\cdot$ bicarbonate $<20 \mathrm{mEq} / \mathrm{L}$ \\
SCORTEN & Lethality $(\%)$ \\
$0-1$ & 3.2 \\
2 & 12.1 \\
3 & 35.8 \\
4 & 58.3 \\
$\geq 5$ & 90 \\
\hline
\end{tabular}

tic pemphigus. After detailed screening, 86 patients were excluded from this study. This study was approved by two institutional research ethics review boards (HCRP \#7737/2011; Plataforma Brasil: Opinion 1.425.047 UEPG; Opinion 1.428.738 HCFMRP-USP).

The collected data included human immunodeficiency virus (HIV) 1 and 2 serology, CD4, total viral load, length of hospitalization, cause of death, body surface area involvement, list of suspect triggering drugs, age, gender, year of diagnosis, comorbidities, alcohol and tobacco use. Analysis of the results of all blood tests performed during admission, such as biochemical, gasometrical, serological, hematological tests. Also, results of skin biopsies performed during admission, in-hospital medical prescriptions, necropsy charts and cause of death statement in the death certificate. Systemic corticosteroids (SCS) and intravenous immunoglobulin (IVIG) given during admission were considered despite dose. SCORTEN was calculated up to the fifth day of hospitalization as the highest sum of up to seven risk factors on the same day when present: age higher than 40 years, malignancy, tachycardia above $120 \mathrm{bpm}$, detachable body surface area higher than $10 \%$, serum urea levels higher than $28 \mathrm{mg} / \mathrm{dL}$, serum glucose levels higher than 252 $\mathrm{mg} / \mathrm{dL}$, and serum bicarbonate levels below $20 \mathrm{mEq} / \mathrm{L}^{21}$

Relative risk (RR) was obtained for comparison of risks among AIDS and non-AIDS population. The association between categorical variables was tested by Fisher's exact test, and for continuous variables by Wilcoxon rank-sum Test. P-values under .05 were considered significant. The risk of death or long hospital stay (>28days) was tested through Poisson's regression, reported as incidence rate ratio (IRR). The Area Under the Curve (AUC) of the Receiver Operating Characteristic (ROC) curve was used to verify the predictive capacity of SCORTEN. AUC greater than 0.70 was considered the minimum acceptable accuracy. Besides being tested on the general population, the SCORTEN was tested amongAIDSand non-AIDS patients separately. Statistical analyses were performed using the software Stata ${ }^{\circledR} 14.2$ - Statistics/Data analysis, StataCorp LP, Texas, USA.

\section{RESULTS}

Sixty-nine patients were included in this study, with age varying between 1 and 74 years. Table 2 shows the different frequencies of the main studied variables among AIDS and non-AIDS patients. The distribution of cases through the years of admission is shown in figure 1 , as well as SCORTEN, HIV, treatment and outcome. All 30 HIV-positive patients were classified as AIDS “C" patients, due to opportunistic infections denoting the severity of the immunodeficiency syndrome, two had CD4 levels between 200 and 500 cells / $\mu$ L with clinical evidence of AIDS (AIDS C2), and the other 28 had CD4 count bellow 200 cells/ $\mu$ L (AIDS C 3 ).

The most frequent suspected offending drugs were: sulfonamides, 19 cases (27.5\%); penicillins, 10 cases (14.5\%), phenytoin, nine cases (13\%); carbamazepine and imidazoles, six cases each (8.7\%); cephalosporins, diclofenac, metamizole, and phenobarbital, five cases each (7.2\%); allopurinol, three cases (4.3\%) and tenoxicam, two cases (2.9\%). Some drugs were associated with higher mortality rates, (Table 3). Patients who presented EN triggered by the use of cephalosporins had a rate (IRR) 11.85 higher for death, $p=.008$, with 
four deaths among five patients (lethality of $80 \%$ ), being present in one third of the deaths in this study. It was the offending drug of the patients with SCORTEN 6 and 7, the highest scores in this study. Angiotensin converting enzyme inhibitors had an IRR for death of
$14.5, p=.016$, with three deaths among six patients. (Table 3).

Ocular sequelae were the only long term complications reported in this study. In total, eleven patients (15.9\%) presented with severe ocular scar or visual dysfunction, needing ophthalmologic

TABLE 2: Characteristics of EN patients with and without Acquired Immunodeficiency Syndrome (AIDS) admitted to a tertiary university hospital in Brazil, from 1990 to 2014

\begin{tabular}{|c|c|c|c|c|}
\hline & Total & Non-AIDS & AIDS & $\mathrm{p}$ \\
\hline & median (IR) & median (IR) & median (IR) & \\
\hline Age (years) & $32(30)$ & $32(46.5)$ & $32.5(12.75)$ & 0.472 \\
\hline \multirow[t]{2}{*}{ Days of Hospitalization } & $16(17)$ & $13(15)$ & $20(17.75)$ & 0.116 \\
\hline & n $(\%)$ & n (\%) & n $(\%)$ & \\
\hline Total & $69(100)$ & $39(100)$ & $30(100)$ & .800 \\
\hline Deaths $\dagger$ & $12(17.4)$ & $7(18)$ & $5(16.7)$ & 1 \\
\hline Stay length $>28$ days & $17(24.6)$ & $8(20.5)$ & $9(30)$ & .419 \\
\hline Ocular sequelae & $11 / 57$ (19.3) & $10 / 32(31.2)$ & $1 / 25(4)$ & $.016^{*}$ \\
\hline Support treatment only & $35(50.7)$ & $22(56.4)$ & $13(43.3)$ & .336 \\
\hline Systemic corticotherapy & $30(43.5)$ & $13(33.3)$ & $17(56.7)$ & .086 \\
\hline IV immunoglobulin & $6(8.7)$ & $4(10.3)$ & $2(6.7)$ & .690 \\
\hline SCORTEN 0 & $3(4.3)$ & $3(7.7)$ & $0(0)$ & .252 \\
\hline SCORTEN 1 & $18(26.1)$ & $11(28.2)$ & $7(23.3)$ & .784 \\
\hline SCORTEN 2 & $18(26.1)$ & $9(23.1)$ & $9(30)$ & .586 \\
\hline SCORTEN 3 & $14(20.3)$ & $6(15.4)$ & $8(26.7)$ & .336 \\
\hline SCORTEN 4 & $11(15.9)$ & $5(12.8)$ & $6(20)$ & .514 \\
\hline SCORTEN 5 & $3(4.3)$ & $3(7.7)$ & $0(0)$ & .252 \\
\hline SCORTEN 6 & $1(1.4)$ & $1(2.7)$ & $0(0)$ & 1 \\
\hline SCORTEN 7 & $1(1.4)$ & $1(2.7)$ & $0(0)$ & 1 \\
\hline Neoplasia § & $3(4.3)$ & $2(2.9)$ & $1(3.3)$ & 1 \\
\hline BSA $>10 \% \S$ & 55 (79.7) & $29(74.6)$ & $26(86.7)$ & .242 \\
\hline HR>120 bpm $\S$ & $16(23.2)$ & $13(33.3)$ & $3(10)$ & $.042 *$ \\
\hline Urea $>28 \mathrm{mg} / \mathrm{dL} \S$ & $36(52.2)$ & $20(51.3)$ & $16(53.3)$ & 1 \\
\hline Serum glucose $>252 \mathrm{mg} / \mathrm{dL} \S$ & $4(5.8)$ & $4(10.3)$ & $0(0)$ & .127 \\
\hline Bicarbonate $<20 \mathrm{mEq} / \mathrm{L} \S$ & $27(39.1)$ & $10(25.7)$ & $17(56.7)$ & $.013^{*}$ \\
\hline$>40$ years $S$ & $25(36.2)$ & $17(43.9)$ & $8(26.7)$ & .207 \\
\hline $13-40$ years & $32(46.4)$ & $11(28.2)$ & $21(70)$ & $.012 *$ \\
\hline$<13$ years & $12(17.4)$ & $11(28.2)$ & $1(3.3)$ & $.012 *$ \\
\hline Male & $47(68.1)$ & $26(66.7)$ & $21(70)$ & .800 \\
\hline Female & $22(31.9)$ & $13(33.3)$ & $9(30)$ & .800 \\
\hline Drugs (all) & $63(91.3)$ & $35(89.7)$ & $28(93.3)$ & .690 \\
\hline ACE-inhibitors & $6(8.7)$ & $5(12.8)$ & $1(3.3)$ & .223 \\
\hline Antibiotics (all) & 37 (53.6) & $20(51.3)$ & $17(56.7)$ & .808 \\
\hline Sulfonamides & $19(27.5)$ & $9(23.1)$ & $10(33.3)$ & .419 \\
\hline Cephalosporins & $5(7.2)$ & $3(7.1)$ & $2(6.7)$ & 1 \\
\hline Quinolones & $1(1.4)$ & $1(2.7)$ & $0(0)$ & 1 \\
\hline Penicillins & $10(14.5)$ & $8(20.5)$ & $2(6.7)$ & .168 \\
\hline Tetracyclines & $1(1.4)$ & $0(0)$ & $1(3.3)$ & .435 \\
\hline Macrolides & $1(1.4)$ & $0(0)$ & $1(3.3)$ & .435 \\
\hline Anticonvulsive drugs (all) & $16(23.2)$ & $10(25.7)$ & $6(20)$ & .775 \\
\hline Phenobarbital & $5(7.2)$ & $4(10.3)$ & $1(3.3)$ & .379 \\
\hline Carbamazepine & $6(8.7)$ & $5(12.8)$ & $1(3.3)$ & .223 \\
\hline Phenytoin & $9(13)$ & $5(12.8)$ & $4(13.3)$ & 1 \\
\hline Allopurinol & $3(4.3)$ & $3(7.1)$ & $0(0)$ & .252 \\
\hline NSAIDs (all) & $10(14.5)$ & $10(15.7)$ & $0(0)$ & $.004^{*}$ \\
\hline Diclofenac & $5(7.2)$ & $5(12.8)$ & $0(0)$ & .064 \\
\hline HAART (all) & $10(14.5)$ & $0(0)$ & $10(33.3)$ & $<.001^{*}$ \\
\hline
\end{tabular}

†Only deaths directly related to epidermal necrolysis; * $\mathrm{p}<0.05$; § SCORTEN risk factors; ; ACE: angiotensin converter enzyme; HR: heart rate; IR: interquartile range; NSAIDs Non-steroidal anti-inflammatory drugs; 
follow-up, with diagnosis such as cicatrizing symblepharon, fornix foreshortening, severe dry eye, and corneal opacity. Usually, more than one diagnosis was present for each patient. Survivors with AIDS presented with better ocular outcome. One (4\%) of the AIDS survivors and $10(31.2 \%)$ of the non-AIDS survivors developed ocular sequelae, $R R=.15$ ( $p=.016)$. The main offending drugs were anticonvulsants, in five patients $(45 \%)$, antibiotics in four patients $(35.4 \%)$ and NSAIDS in two patients (18.2\%).

All patients with ocular sequelae presented SCORTEN $<4$. Four survivors (30.7\%) presented ocular sequelae after EN in up to $10 \%$ of the body surface area (SJS), while 7 survivors presented ocular sequelae after EN in more than $10 \%$ of the body surface area (SJS-TEN overlap or TEN), $p=1.0$ ).

The median length of hospitalization was of 30 (32), going from 1 to 210 days. Fifteen deaths occurred, with 3 deaths (20\%) non-related to EN in AIDS patients with severe concomitant illnesses.
A total of $12(17.4 \%)$ patients died as a direct consequence of SJSTEN. Seven patients $(20 \%)$ died among the 35 who received only support treatment. Five patients (17.9\%) died among the 28 that received systemic corticotherapy (SC). Six patients were treated with IV immunoglobulin (IG) therapy, none died. Among these, two patients received both SC and IG, and four patients received only IG. IG was prescribed as $1 \mathrm{~g} / \mathrm{kg}$ per day for 4 consecutive days. SC varied among pulse therapy with $1 \mathrm{~g}$ of methylprednisolone for 3 days, oral prednisone $0.5-2 \mathrm{mg} / \mathrm{kg}$ for 20 days, and even minimal prednisone doses such as $10 \mathrm{mg} /$ day for 5 days for an adult. The length of SC varied from 1 to 20 days. Distribution of treatment by age and year of admission, with SC, IG or both is shown in figure 2 .

Figure 3 illustrates the great variety of clinical presentation of the cases.

SCORTEN showed an excellent performance as death predictor with an AUC of 0.90 , with $95 \%$ confidence interval (CI) rang-

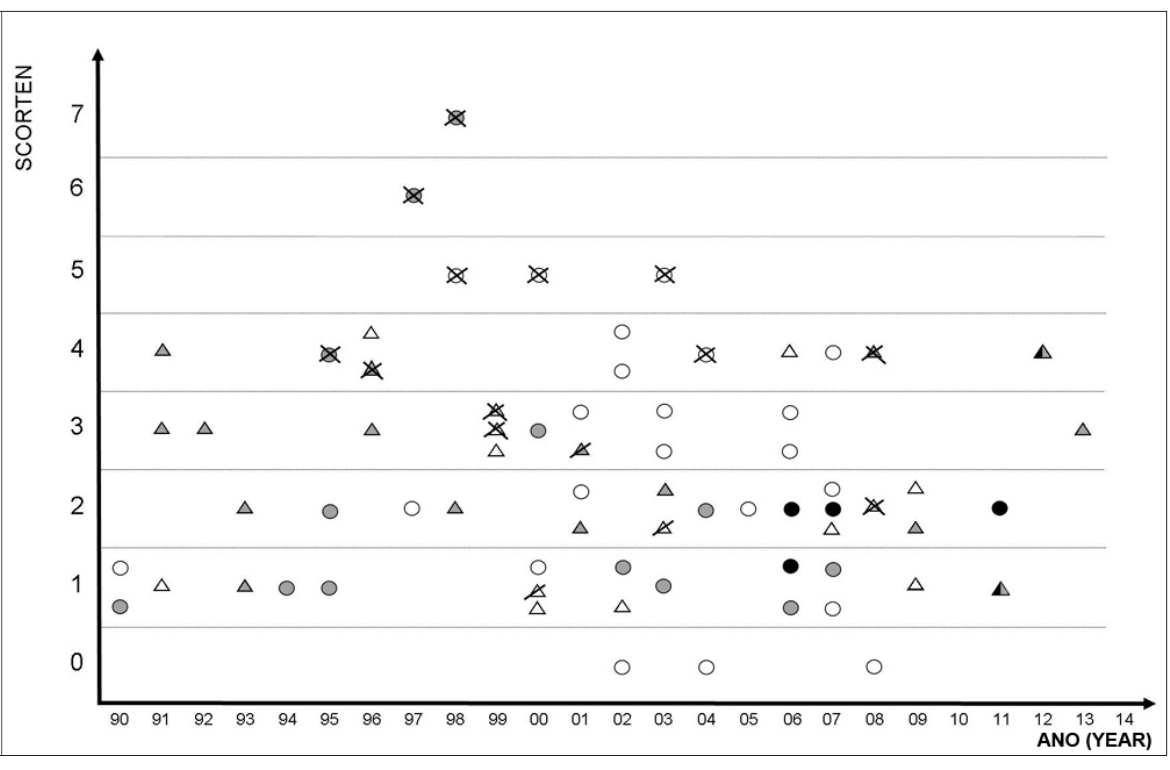

Figure 1: Epidermal Necrolysis. Distribution of cases from a high complexity hospital in Brazil from January of 1990 to December of 2014. Triangles: Patients with Acquired Immunodeficiency Syndrome (AIDS). Circles: Patients without AIDS. X: death as direct consequence of SJS-TEN. Slash: death by unrelated cause. White: support treatment only. Grey: systemic corticotherapy. Black: IV immunoglobulin

TABLE 3: Risk factors for death and long hospital stay ( $>28$ days), among cases of epidermal necrolysis admitted to a tertiary level university hospital in Brazil, from 1990 to 2014, with incidence rate ratios obtained through Poisson's regression

\begin{tabular}{lccccccc} 
Risk factors & $\begin{array}{c}\text { Total } \\
\mathbf{n}(\%)\end{array}$ & $\begin{array}{c}\text { Deaths } \\
\mathbf{n}(\%)\end{array}$ & IRR (95\%CI) & $p$ & $\begin{array}{c}\text { Long Hospital } \\
\text { Stay n (\%) }\end{array}$ & IRR (95\%CI) & $p$ \\
\hline AIDS & $28(40.6)$ & $5(17.8)$ & $2.02(0.48-8.55)$ & .341 & $9(32.1)$ & $1.60(0.78-3.26)$ & 0.196 \\
Male & $47(69.6)$ & $7(16.7)$ & $0.63(0.16-2.48)$ & .508 & $14(29.2)$ & $1.40(0.62-3.13)$ & 0.420 \\
Age > 40 & $25(36.2)$ & $7(28)$ & $1.31(0.32-5.37)$ & .700 & $8(32)$ & $1.23(0.58-2.59)$ & 0.589 \\
Neoplasia & $3(4.3)$ & $2(66.7)$ & $2.96(0.17-50.44)$ & .453 & $2(66.7)$ & $1.82(0.34-9.79)$ & 0.482 \\
Drugs & & & & & & \\
Cephalosporins & $5(7.2)$ & $4(80)$ & $11.85(1.89-74.4)$ & $.008^{*}$ & $2(40)$ & $1.15(0.31-4.29)$ & .829 \\
ACEI & $6(8.7)$ & $3(50)$ & $14.48(1.64-128.25)$ & $.016^{*}$ & $3(50)$ & $1.41(0.41-4.84)$ & .581 \\
Phenobarbital & $5(7.2)$ & $1(20)$ & $2.03(0.11-35.94)$ & .629 & $3(60)$ & $1.91(0.57-6.42)$ & .296 \\
Phenytoin & $9(13)$ & $2(22.2)$ & $3.50(0.42-29.29)$ & .248 & $3(33.3)$ & $1.23(0.45-3.36)$ & .691 \\
Sulfonamides & $19(27.5)$ & $3(15.8)$ & $1.54(0.11-20.71)$ & .744 & $4(21)$ & $0.70(0.26-1.90)$ & .482 \\
Carbamazepine & $6(8.7)$ & $1(16.7)$ & $1.91(0.09-38.5)$ & .673 & $3(50)$ & $0.86(0.21-3.47)$ & .833 \\
\hline
\end{tabular}

* - < <.05; ACEI: Angiotensin converting enzyme inhibitors; AIDS: Acquired immunodeficiency syndrome; CI: Confidence Interval; IRR: incidence rate ratio 
ing from .81 to .99 (Figure 4). The performance of SCORTEN was better among non-AIDS patients than in AIDS patients $(p=.022)$, non-AIDS AUC=.99 (95\% CI=.96-1.00), AIDS AUC=.74 (95\% CI .53.95), figure 5 . The empirical optimal cut-off point for SCORTEN was 3.5 , with $75 \%$ sensibility and $88 \%$ specificity, area under ROC curve at cut-off point of 0.81 . The same optimal cut-off point was obtained non-AIDS patients, 3.5, with sensibility of $100 \%$ and specificity of $91 \%$, area under ROC curve at cut-off point of 0.95. Among AIDS patients, the optimal cut-off point for SCORTEN was 2.5, with $80 \%$ sensibility and $60 \%$ specificity, and an area under ROC curve at cutoff point of 0.70 .

\section{DISCUSSION}

Batsuji-Garin et al (2000) $)^{15}$ studied 165 patients to develop SCORTEN and 75 patients to validate it. In his study, he obtained an AUC of 0.84 for SCORTEN, validating the use of SCORTEN as a death predictor, Sekula et al, ${ }^{22}$ with a total of 166 patients found an AUC of .75, considering SCORTEN to be applicable to the European population. This study included 69 patients and is to date the biggest study of the kind in the American continent. The AUC obtained among all patients of .91 confirms that SCORTEN is an excellent lethality predictor in the Brazilian population. Although smaller (.74), the AUC obtained among the AIDS patients was high enough for the
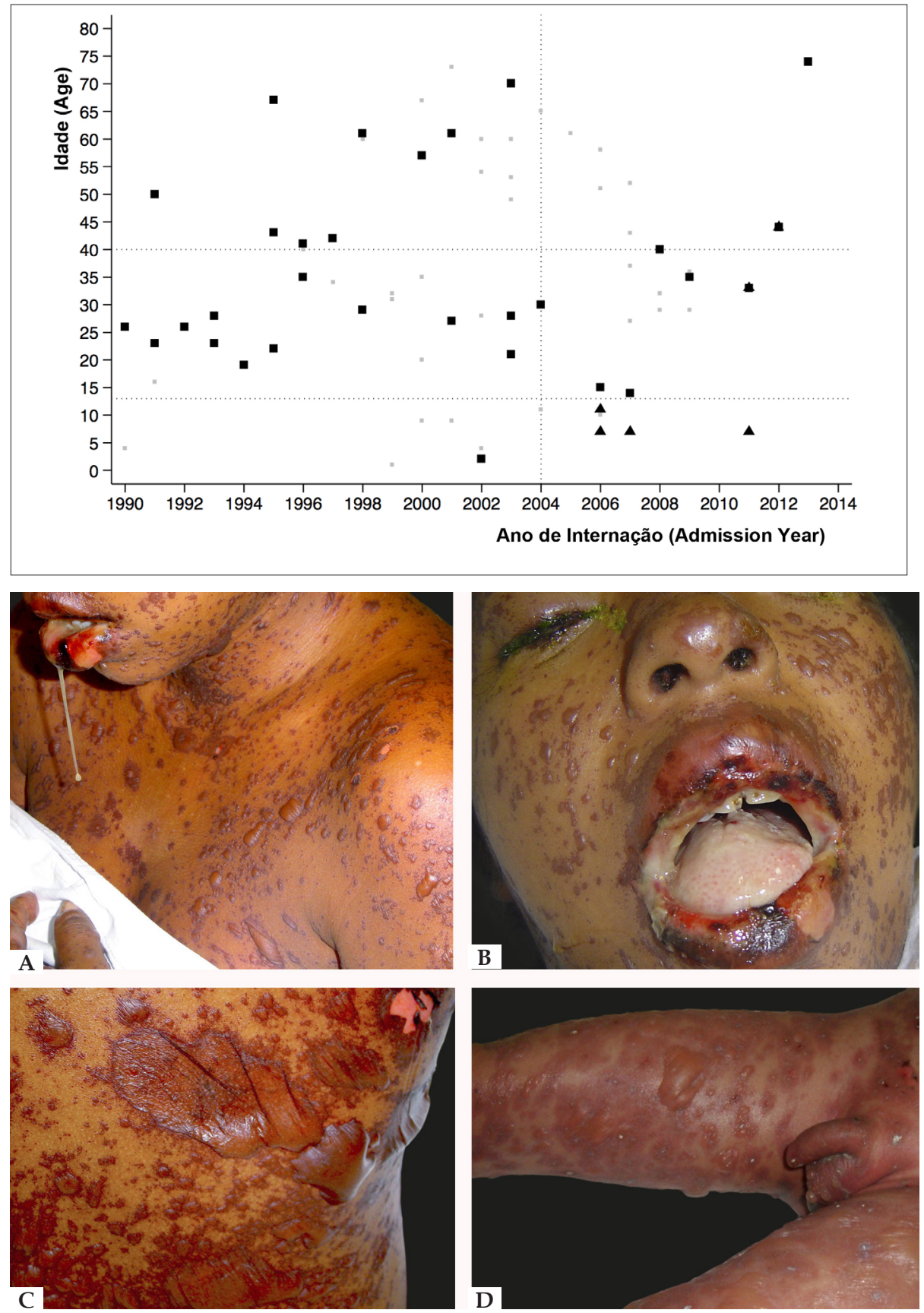

Figure 2: Epidermal Necrolysis. Cases from a high complexity hospital in Brazil from January of 1990 to December of 2014, distributed according to age at admission. Small grey squares: support treatment only. Black squares: systemic corticotherapy. Black triangles: IV immunoglobulin

FIgURE 3: Toxic Epidermal Necrolysis (TEN). A - Detachable skin portion above $30 \%$ of total body surface area. Severe involvement of mucous membranes, severe dysphagia causing sialorrhea, SCORTEN=3. B - Details of mucous involvement with severe ocular involvement. Ocular sequelae occurred, with formation of bilateral cicatrizing symblepharon and severe dry eye. C - Detail of a bulla. D - Child with TEN with thiabendazole as offending drug, with skin detachment of more than $60 \%$ percent of the total body surface area, with severe involvement of trunk, limbs and genitalia. SCORTEN=1 


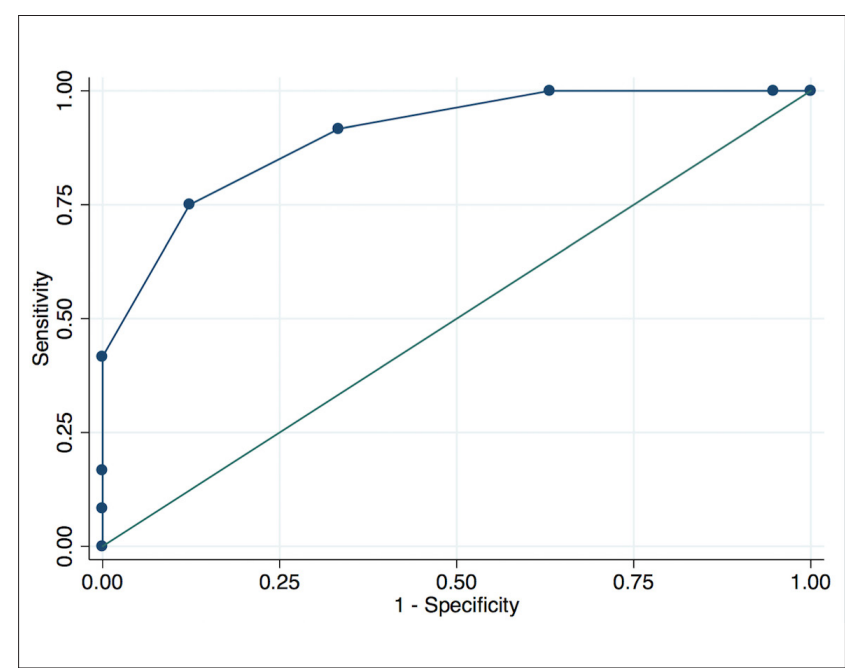

FIGURE 4: Receiver Operating Characteristic (ROC) curve analysis of SCORTEN in cases admitted to a tertiary level university hospital in Brazil, from 1990 to 2014. Black: SCORTEN, AUC: 0.90, CP: 3.5 (0.75/0.88); Grey: reference line, AUC: 0.50, CP: 0.5/0.5. AUC: Area Under Curve. CP: Cut-point SCORTEN (sensitivity/specificity)

SCORTEN to be considered reliable in this population.

This study was conducted in a tertiary level university hospital, in which, in admissions of high complexity cases, the laboratorial parameters needed for SCORTEN calculation are performed as routine (arterial blood gas test, renal function, and serum glucose). The authors agree that, in all EN cases, the patient should ideally be admitted to an isolation hospital bed of a tertiary level hospital for high complexity support, until stabilization of the condition for hospital discharge. Maybe the hospitalization in a university tertiary level hospital, which are habituated to the management of high complexity cases, might be the cause for the slightly better global prognosis than the one predicted by SCORTEN. As seen on figure 1, from 1990 to 1998, there was a tendency to prescribe SC. After positive results of the Miami study published in 2004, the use of IG was implemented with fixed doses of $1 \mathrm{~g} / \mathrm{kg} /$ day for 4 consecutive days (Figures 1 and 2). ${ }^{10}$ In contrast to this, the prescribed doses of SC varied greatly during the period observed, without any standardization. One of the limitations of this study was that data were collected since a period when the calculation of SCORTEN on the first five days of admittance was not yet instituted. Therefore, many of the patients admitted on the 90's had only one dosage of venous gases on admission, which was used as the only dosage of bicarbonate. On the other hand, even in the $90^{\prime}$ s, all critical patients, including those in need of mechanical ventilation or with elevated respiratory rates, were monitored with sequential bicarbonate measurements, providing even more precise data.

Unfortunately, SCORTEN was not assessed routinely at the hospital of this study until 2007, when Wambier et al ${ }^{23}$ showed that patients with higher SCORTEN were receiving only support treatment while lower SCORTEN patients were receiving SC and/

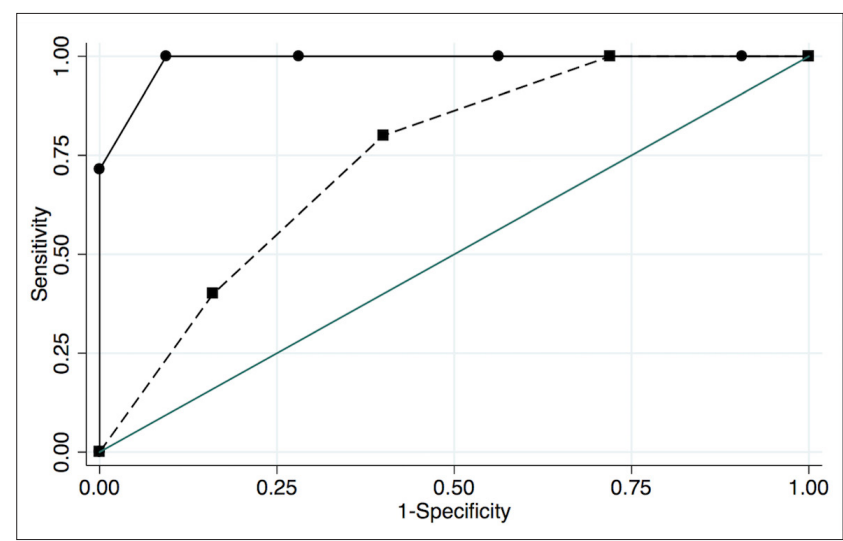

FIGURE 5: A - Receiver Operating Characteristic (ROC) curve analysis of SCORTEN in cases admitted to a tertiary level university hospital in Brazil, from 1990 to 2014. Solid: SCORTEN among patients without SIDA, AUC:0.99; CP: 3.5 (1.0/0.91). Dashes: SCORTEN among patients with AIDS, AUC:0.74; CP: 2.5 (0.8/0.6) Light grey: reference line, AUC:0.50; CP: 0.5/0.5 AIDS: Acquired Immunodeficiency Syndrome. AUC: Area Under Curve. CP: Cut-point SCORTEN (sensitivity/specificity)

or IG. ${ }^{23}$ This prompted a review of the approach on EN patients and altered internal procedures so as to analyze the prognosis according to SCORTEN before starting immunotherapy with IG or SC, reserving this therapy for patients with SCORTEN $>2$. Patients with AIDS usually received higher doses of corticoids in pulse therapy, for they were admitted to another sector of the hospital, of intensive care for AIDS patients.

According to the optimal cut-off point obtained by the ROC analysis regarding SCORTEN, of 2.5 for AIDS and 3.5 for non-AIDS and overall, to the endpoint of death related to $\mathrm{EN}$, the following cut-offs for clinical decision of prescribing immunossupressive treatments could be used, SCORTEN $>3$, or, for a safer option, SCORTEN $>2$. The SCORTEN scores of highest probability of lethality in our data were 5, 6 and 7, with 100\% lethality rate.

All patients with HIV included in this studied fulfilled criteria to AIDS diagnosis, either by AIDS-defining conditions or CD4 count, and were classified as AIDS C2 and AIDS C3. HIV-positive patients without AIDS were not studied because there were none in the period.

\section{CONCLUSION}

Based on the data from this study, SCORTEN is a valid predictor of mortality in the Brazilian population, including patients with AIDS. The routine calculation of SCORTEN in these patients is recommended to help guiding treatment decision, especially in the decision of prescribing treatments such as SC pulse therapy or IVIG. Prospective, randomized trials are needed to compare the efficacy of such treatment modalities in EN. $\square$ 


\section{REFERENCES}

1. Borchers AT, Lee JL, Naguwa SM, Cheema GS, Gershwin ME. Stevens-Johnson syndrome and toxic epidermal necrolysis. Autoimmun Rev. 2008;7:598-605.

2. Bastuji-Garin S, Rzany B, Stern RS, Shear NH, Naldi L, Roujeau JC. Clinical classification of cases of toxic epidermal necrolysis, Stevens-Johnson syndrome, and erythema multiforme. Arch Dermatol. 1993;129:92-6.

3. Chave TA, Mortimer NJ, Sladden MJ, Hall AP, Hutchinson PE. Toxic epidermal necrolysis: current evidence, practical management and future directions. $\mathrm{Br} \mathrm{J}$ Dermatol. 2005;153:241-53.

4. Valeyrie-Allanore L, Roujeau J-C. Epidermal Necrolysis (Stevens-Johnson Syndrome and Toxic Epidermal Necrolysis). In: Goldsmith LA, Katz SI, Gilchrest $B A$, Paller AS, Leffell DJ, Wolff K, editors. Fitzpatrick's dermatology in general medicine. 8th ed. New York, NY: The McGraw-Hill Companies, Inc; 2012.

5. IIling PT, Vivian JP, Dudek NL, Kostenko L, Chen Z, Bharadwaj M, et al. Immune self-reactivity triggered by drug-modified HLA-peptide repertoire. Nature. 2012;486:554-8.

6. Rappersberger K, Foedinger D. Treatment of erythema multiforme, Stevens-Johnson Syndrome, and toxic epidermal necrolysis. Dermatol Ther. 2002;15:397-408.

7. Chang YS, Huang FC, Tseng SH, Hsu CK, Ho CL, Sheu HM. Erythema multiforme, Stevens-Johnson syndrome, and toxic epidermal necrolysis: acute ocular manifestations, causes, and management. Cornea. 2007;26:123-9.

8. Schneck J, Fagot JP, Sekula P, Sassolas B, Roujeau JC, Mockenhaupt M. Effects of treatments on the mortality of Stevens-Johnson syndrome and toxic epidermal necrolysis: A retrospective study on patients included in the prospective EuroSCAR Study. J Am Acad Dermatol. 2008;58:33-40.

9. Kardaun SH, Jonkman MF. Dexamethasone pulse therapy for Stevens-Johnson syndrome/toxic epidermal necrolysis. Acta Derm Venereol. 2007;87:144-8.

10. Trent JT, Kirsner RS, Romanelli P, Kerdel FA. Analysis of intravenous immunoglobulin for the treatment of toxic epidermal necrolysis using SCORTEN: The University of Miami Experience. Arch Dermatol. 2003;139:39-43.

11. Prins C, Kerdel FA, Padilla RS, Hunziker T, Chimenti S, Viard I, et al. Treatment of toxic epidermal necrolysis with high-dose intravenous immunoglobulins: multicenter retrospective analysis of 48 consecutive cases. Arch Dermatol. 2003;139:26-32.

12. Kirchhof MG, Miliszewski MA, Sikora S, Papp A, Dutz JP. Retrospective review of Stevens-Johnson syndrome/toxic epidermal necrolysis treatment comparing intravenous immunoglobulin with cyclosporine. J Am Acad Dermatol. 2014;71:941-7.
13. Pehr K. The EuroSCAR study: cannot agree with the conclusions. J Am Acad Dermatol. 2008;59:898-9.

14. Creamer D, Walsh SA, Dziewulski P, Exton LS, Lee HY, Dart JKG, et al. UK guidelines for the management of Stevens-Johnson syndrome/toxic epidermal necrolysis in adults 2015. J Plast Reconstr Aesthet Surg. 2016;69:e119-53.

15. Bastuji-Garin S, Fouchard N, Bertocchi M, Roujeau JC, Revuz J, Wolkenstein P. SCORTEN: a severity-of-illness score for toxic epidermal necrolysis. J Invest Dermatol. 2000;115:149-53.

16. Trent JT, Kirsner RS, Romanelli P, Kerdel FA. Use of SCORTEN to accurately predict mortality in patients with toxic epidermal necrolysis in the United States. Arch Dermatol. 2004;140:890-2.

17. Kim KJ, Lee DP, Suh HS, Lee MW, Choi JH, Moon KC, et al. Toxic epidermal necrolysis > analysis of clinical course and SCORTEN-based comparison of mortality rate and treatment modalities in Korean patients. Acta Derm Venereol. 2005;85:497-502

18. Cartotto R, Mayich M, Nickerson D, Gomez M. SCORTEN accurately predicts mortality among toxic epidermal necrolysis patients treated in a burn center. $J$ Burn Care Res. 2008;29:141-6.

19. Zhu QY, Ma L, Luo XQ, Huang HY. Toxic epidermal necrolysis: performance of SCORTEN and the score-based comparison of the efficacy of corticosteroid therapy and intravenous immunoglobulin combined therapy in China. J Burn Care Res. 2012;33:e295-308.

20. Apps.who.int [Internet].World Health Organization (WHO). International Classification of Diseases (ICD). Int Classif Dis. 2015 [cited 2015 Dec 28]. Available from: http://apps.who.int/classifications/icd10/browse/2016/en\#/A30.

21. Guégan S, Bastuji-Garin S, Poszepczynska-Guigné E, Roujeau JC, Revuz J. Performance of the SCORTEN during the first five days of hospitalization to predict the prognosis of epidermal necrolysis. J Invest Dermatol. 2006;126:272-6.

22. Sekula P, Liss Y, Davidovici B, Dunant A, Roujeau JC, Kardaun S, et al. Evaluation of SCORTEN on a cohort of patients with Stevens-Johnson syndrome and toxic epidermal necrolysis included in the RegiSCAR study. J Burn Care Res. 2011;32:237-45.

23. Wambier CG, Paschoal RS, Roselino AM, Foss NT. Análise da aplicabilidade do SCORTEN: escala de avaliação prognóstica do Complexo Síndrome de StevensJohnson / Necrólise Epidérmica Tóxica em um Hospital Universitário Terciário. In: Pôsteres apresentado no 62. Congresso da Sociedade Brasileira de Dermatologia: 2007 set 1-5; São Paulo, Brasil. An Bras Dermatol. 2007;82(Supl 1):S173-4.

\section{AUTHORS'CONTRIBUTIONS}

Carlos Gustavo Wambier $\quad$ (D) ORCID 0000-0002-4636-4489

Statistical analysis; Approval of the final version of the manuscript; Conception and planning of the study; Elaboration and writing of the manuscript; Obtaining, analyzing and interpreting the data; Effective participation in research orientation; Intellectual participation in propaedeutic and/or therapeutic conduct of the cases studied; Critical review of the literature; Critical review of the manuscript

Thaís Angélica Hoekstra

D ORCID 0000-0002-9472-7811

Statistical analysis; Approval of the final version of the manuscript; Elaboration and writing of the manuscript; Obtaining, analyzing and interpreting the data; Critical review of the literature

Sarah Perillo de Farias Wambier

ORCID

0000-0002-0311-3989

Approval of the final version of the manuscript; Conception and planning of the study; Elaboration and writing of the manuscript; Intellectual participation in propaedeutic and/or therapeutic conduct of the cases studied; Critical review of the literature; Critical review of the manuscript
Roberto Bueno Filho
(iD) ORCID
0000-0003-2871-0306

Approval of the final version of the manuscript; Obtaining, analyzing and interpreting the data; Intellectual participation in propaedeutic and/or therapeutic conduct of the cases studied $\begin{array}{lll}\text { Fernando Crivelenti Vilar } & \text { (iD) ORCID } 0000-0001-8232-5375\end{array}$

Approval of the final version of the manuscript; Obtaining, analyzing and interpreting the data; Intellectual participation in propaedeutic and/or therapeutic conduct of the cases studied Renato Soriani Paschoal (iD) ORCID 0000-0003-0493-9966

Approval of the final version of the manuscript; Elaboration and writing of the manuscript; Obtaining, analyzing and interpreting the data; Effective participation in research orientation; Critical review of the literature

Ana Maria Roselino $\quad$ (iD) ORCID 0000-0002-2709-1825

Approval of the final version of the manuscript; Conception and planning of the study; Intellectual participation in propaedeutic and/or therapeutic conduct of the cases studied

Marco Andrey Cipriani Frade $\quad$ (iD) ORCID 0000-0003-2700-5971

Approval of the final version of the manuscript; Conception and planning of the study; Intellectual participation in propaedeutic and/or therapeutic conduct of the cases studied Norma Tiraboschi Foss

(iD) ORCID 0000-0003-3672-2614

Approval of the final version of the manuscript; Conception and planning of the study; Effective participation in research orientation; Intellectual participation in propaedeutic and/or therapeutic conduct of the cases studied; Critical review of the manuscript

How to cite this article: Wambier CG, Hoekstra TA, Wambier SPF, Bueno Filho R, Vilar FC, Paschoal RS, Roselino AM, Frade MAC, Foss NT. Epidermal necrolysis: SCORTEN performance in AIDS and non-AIDS patients. An Bras Dermatol. 2019;94(1):17-23. 